\title{
Gaza City: A Profound Personal Journey
}

\author{
Norm Dean \\ Deputy Director \\ Yew Chung Education Foundation \\ Hong Kong \\ normdean4@gmail.com
}

\begin{abstract}
In 2012 I made two trips into Gaza City to work with staff of the American International School, Gaza. My employing company at the time had a contract with USAID to support the school in its development and progress toward accreditation. My role was to undertake an analysis of the school academic program and develop an improvement plan with the leadership group and board, incorporating pedagogical training for teaching staff that had extremely limited opportunities to external support and expertise due to isolation from the outside world. What I experienced in my visits to Gaza had a profound effect on me as a person and as an educator as I witnessed the passion and commitment of teachers working with students in the most trying of circumstances. The first three days of my initial visit coincided with a serious escalation of hostilities, and observing the school in operation throughout this time was inspiring and terrifying at the same time. My paper will recount my experience working alongside colleagues in challenging facilities, with minimal resources, amid the constant threat of danger. It will tell the story of how teacher commitment and dedication, matched by a strong student desire to learn can create truly inspiring learning communities. I will focus partly on the pedagogical training to assist teachers in sustaining an engaging learning environment in this environment, but also on the centrality of the school culture in a hostile environment where hope and aspiration emerge, and bring hope for the future.
\end{abstract}

\section{Introduction}

In 2006 I moved to Dubai to work with a company that owned and managed international schools in the Middle East. I left the comfort of my home country and extensive professional networks to take on a challenging role in a new country with a completely different culture and school system. I well remember my early morning arrival into Dubai in August 2006 where I was confronted by heat, dust and sandstorms like I'd never experienced. I was to learn in time of the oppressive summer weather that inflicts torment upon this region, of Arab hospitality and a culture rich in history and tradition and innovation, which had not appeared in my school textbooks, with the exception of the pyramids of course!

Dubai is a melting pot of cultures and ethnicities with a diversity of people, religions and ideas. It is however, like its neighboring countries, a deeply conservative Islamic society. So while my immediate impressions were to do with the natural and physical environment, I quickly began to 
appreciate and engage with the subtler, but overwhelmingly powerful reality of a social construct radically different from that which I'd left behind. I was soon to learn how ignorant I was of so many things, most acutely that my "westernized" view of history was not a universally shared view.

I was soon confronted by experiences that were totally new to me as I lived in a community and worked with colleagues and students from around the world, including those who had fled war-torn countries within the region, and those who could not return to the land of their birth. I became increasingly aware of the prejudices and prevailing cultural biases, which deeply affected the life chances of so many. I learnt that a passport could be used as a prison sentence. I was constantly forced to assess my western paradigm of the world because in these communities a different worldview prevailed, not better nor worse, simply different to mine. The challenge for me was to open my heart and mind to these new insights and value the difference as enrichment. One constant I did find, expressed in multiple forms, was the hope and desire of parents everywhere for their children to succeed in school and have the opportunity to live a prosperous and happy life. Prosperous and happy did not necessarily equate to financial wealth, but rather the hope of safety, freedom to make choices and a place to call home.

During my eight years in the region I traveled extensively to many schools in surrounding countries and these experiences reinforced my sense of shared good and emerging best practice not being the province of any one approach, school or system. The overwhelming impression from each of these visits was that quality schools the world over, regardless of location or facilities, student demographics or access to resources, all seek to instill in students a set of values and attitudes that promote citizenship; intellectual curiosity; environmental empathy; and an aspiration to achieve their potential. Some of these schools were in volatile locations and I was deeply affected by the impact of teachers in these environments who gave so much of themselves to bring joy, knowledge and inspiration to the students in their care.

In 2013 I wrote a chapter for a book titled Learning and Teaching about Islam: Essays in Understanding ${ }^{l}$. My chapter looked at the practice of establishing an international school in an Islamic setting, in which I make the point that "a transplant alone will not do". My point is selfexplanatory, but nevertheless worth repeating, and that is for those of us working in schools within host countries it is imperative we take account of local societal and cultural/religious norms as we infuse new ideas and ways of thinking, for to not to do so leaves us susceptible to arrogance, ignorance and intolerance.

It was within this new and international context that one of my most profound personal and professional experiences occurred, visiting Gaza City twice in 2012 to support staff in a K-12 international school. What I will share is not research-based, nor is it an academic study, but rather a personal account of being with people, real people, with hopes, aspirations and community, and observing how they live, work and learn in a violent place. I make no political statement, but rather an observation on the incredible resilience of lives being lived in a hostile environment, tempered by the beauty of human endeavor and the enduring power of education. The "heroes" of my story are the administrators, teachers, students, families and communities who struggle and persevere in circumstances of severe challenge, and at times, warfare. My time in Gaza was brief, but truly profound.

My employer had been working in partnership with this particular school over a number of years through an education project sponsored by USAID. Due to regular outbreaks of violence and geopolitics within the region this relationship had lapsed, but in 2012 the relationship was re-

${ }^{1}$ Ellwood, C. (Ed.). (2012) Learning and Teaching about Islam: Essays in Understanding. Melton, Woodbridge, UK: John Catt Educational. www.johncattbookshop.com/learning-and-teaching-aboutislam-essays-in-understanding 
activated. Some years earlier the school had operated on a spacious site with state of the art infrastructure and facilities, but tragically had been destroyed by an Israeli bomb and rendered inoperable. Additionally, the school had previously been subject to threats and sporadic attacks from Islamic fundamentalists due to the co-educational nature of the program. Here then was a school community touched by violence and loss determined to pursue its mission and purpose, despite the volatile environment surrounding it. Following its destruction the school had resumed operations in the Gaza City precinct within converted apartment buildings, due to the efforts of a dedicated number of business people, community and staff. I was asked to visit the school in March 2012 to undertake an analysis of school readiness to undergo an accreditation exercise. I made a second trip in May 2012 to provide teacher training and speak at the Year 12 Graduation Ceremony.

Entering the Gaza strip is not a straightforward exercise, to say the least. Crossing the border from Israel is understandably through very heavy security. Once through the various checkpoints a steel door slammed shut behind me and ahead was a long, wire enclosed path through no man's land to the Fatah checkpoint (Fatah being officially recognized by Israel and thus authorized to permit entry to Gaza). The slamming of the door is quite foreboding and many Palestinians referred to being in the world's largest outdoor prison, for the concrete walls and the heavily patrolled port exclusion zone ensure no-one leaves unless Israel deems it so. A short drive in a rusty taxi took me to a Hamas checkpoint, where following another interrogation I finally entered the Gaza Strip. First impressions always leave an indelible mark, and this experience most certainly did. My senses were instantly on overload as I took in the new world around me. It was difficult to believe that only a few hours earlier I had been in a modern, cosmopolitan city (Jerusalem) and now I was seeing destruction and poverty all around me, a place where a donkey and cart were more prevalent than cars due to petrol shortages, and where generators were continually whirring due to unreliable power supplies. There was dust everywhere and seemingly every building was damaged in some way. Roads had craters in them from previous bombings and electricity wires hung precariously between poles at distorted angles. Some of the places I was to visit while in Gaza were virtual shanty towns, equal in human depravation to any I'd seen elsewhere in the world. The scale of human misery and physical decay was immense, and it was not yet winter.

As I was being driven to my hotel, where I was the only guest for the first few days, the unmistakable sound of missiles filled the air. I did not know it at the time but missile exchanges would continue for four days and result in the loss of many lives in Gaza, and a smaller number in Israel. It was the most serious escalation of violence that they had seen for many years and immediately the streets were deserted, but the silence was not for long. I had never experienced anything like this before and it was initially more surreal than scary, and by the fourth day my sense of equilibrium was wavering. At my hotel I was assured I would be safe so long as I didn't venture out in the evenings or visit certain "hotspots". I did not need to be told twice. This was my introduction to Gaza.

The next morning I was driven to the school for the first time where the decision had been made to continue with the normal program. The administrators, who had experienced this all before, were confident the targeted areas within the city would ensure the school remained a safe haven. The school, as mentioned earlier, is located in the city itself, within three adjoined apartment blocks. The conditions are cramped and there is minimal inside and outside play space for the students aged 4 to 18. With the exception of two Americans, the teaching faculty was all Palestinian, and while they had qualifications in particular disciplines, most had received no formal teacher training but did a wonderful job through sheer commitment and adaptation. As exploding missiles could be heard in the distance I moved around the school observing a school doing what all good schools do, catering for the learning needs of its pupils. How, I wondered, did this school function in such a challenging environment?

My initial observations highlighted some shortcomings in teacher pedagogy and the learning experience for students, partly due to lack of training and knowledge, but also largely driven by the physical limitations of classrooms and resources, including intermittent internet. Even seemingly

Journal of Contemporary Issues in Education, 2016, 11(1), pp. 79-85 
simple activities were very difficult to undertake and there was a heavy reliance on textbooks, which were in poor condition and outdated. In the secondary school, many science experiments were compromised or simply impossible as access to chemicals was limited for security reasons. Art was in a similar position with paints and other materials on the banned list.

In this challenging setting a most remarkable thing happened as I moved around the school; teachers continually sought me out for conversations about how they could improve their practice, as they were anxious to ensure they were doing their best for their students. What I encountered was a learning community dedicated to improvement for the sake of their students, no matter what it took. The students themselves were seekers of knowledge, keen to learn, anxious about examinations and despite enormous deprivation, in my eyes at least, motivated to learn. I worked with the administration and teachers to develop a pedagogy training program, all the while remaining cognizant of the challenge ahead for the teachers in adapting to new methodologies. Despite the missiles coming and going, despite the resources they didn't have, there was a huge amount they did have. I was to learn more about that in the coming days, my next visit and through ongoing communication.

Many stories resonated with me that week, but one that was particularly moving was hearing of a rare sponsored trip out of Gaza for senior students to attend a global student conference in Ireland. After a number of aborted attempts to cross the border into Egypt for their flight, the students finally made their way to Ireland. After a harrowing start to their journey, the students were overcome with joy and humility at how easily they entered this foreign country, and how warmly young people representing many different nationalities and cultures received them. For the Gaza students it was a profound experience on a human level that touched them deeply. Forums such as this can create relationships which build bridges of understanding and hope. The other student delegates initially had little knowledge of Islam, of Palestine, the plight of Gaza, or reasons for the enduring conflict but through dialogue, awareness and empathy emerged.

Missiles exploded and sirens wailed continuously for my first four days yet the school operated as normal despite all that was happening. The children could tell through the open windows whether the missiles were outgoing or incoming and still the teachers taught and still the students learnt. On the fourth day a ceasefire was brokered and to my utter amazement, given the loss of life and scale of damage, the rhythm of life resumed, seemingly without missing a beat. I saw weddings, bustling markets, families at the beach, children playing on the streets, and heavy machinery shifting piles of concrete and debris. At school, the lessons continued. The resilience was remarkable and I could only think that this capacity to rebound and move forward despite deep tensions and overwhelming destruction must be borne out of a strong belief system, and that resilience must be passed from one generation to the next. I prepared to leave at the end of the week and as I did I began to ponder the uniqueness of what I had experienced and wondered about the amazing capacity of children to learn when supported and encouraged by teachers who care for them deeply, despite many obstacles. I continually asked myself how learning continued in such a hostile environment. While I don't know the answer I suspect beyond the school culture it had something to do with self-identity and assurance that grows from a strong and aligned home-school partnership. I was due to visit again in another month and as I left I wondered what it was I could impart to these teachers that could possibly be as profound as what they had shared with me. In a broken world of violence and loss, they had demonstrated integrity and joy through passion and commitment to their students, creativity and ingenuity in providing meaningful learning experiences, and a strong desire to be continuous learners.

If I based my judgments of the quality of teaching and learning against international best practice (western paradigm) then there was much that needed development which included: very basic classroom techniques, voice modulation, individualized goal setting, student inquiry, assessment and reporting, and curriculum. At this time there were no curriculum course descriptors written, limited program objectives and scope and sequence, and policies and procedures were very rudimentary. The curriculum however, even at this developmental stage was interdisciplinary in nature and provided a 
broader perspective on issues than any national curriculum alone would do. Importantly, the curriculum was adapted in a way which reflected and respected the culture, history and beliefs of Islamand the Palestinian people, while at the same time providing a basis for inquiry and research. The curriculum was empowering, giving students the belief and strategies to think critically and problem-solve within their own cultural context. All of this was not easy for the teachers who by tradition and culture were pre-disposed to a teaching construct of directed learning and thus for them the journey was a challenge and would require continual commitment and support. For students to be critical thinkers, they first need to understand and be confident within themselves, for only then can they reach out and be open to the views of others. The centrality of curriculum cannot be overstated. Unless it is a tool for indoctrination, it has the power to be a catalyst for perspectives, analysis and debate in the search for common ground and for uncovering shades of grey in a world characterized as black and white.

While the taught and planned curriculum was to a certain extent immature and evolving, what was evident was that this mattered less when supplemented by personal qualities, passion and values of teachers who were totally congruent with the school mission. In a hostile environment, the teachers and the students had a purpose and shared vision for a better future, which galvanized their collective efforts.

There was something bigger than all of that happening here and it was borne out on my next visit in particularly memorable ways. I conducted training sessions and what I discovered was that the teachers were hungry for anything that would enhance their practice, and they were incredibly passionate. They had a willingness to embrace new ideas and were keen to share with others.

One evening, the school held a community event in which senior students had the opportunity to be entrepreneurs and create a marketplace for the sale of products or ideas. While this was an overwhelmingly fun activity, what was so evident to me was the support of parents and the community at large. This was curriculum in action, a real-world application of practice and therefore meaningful and enduring. Many of the parents I spoke to expressed appreciation for the school and activities such as this for they recognized their reality was either to create, or wither and perish. Their belief is that only through education can a better future can be created. Teachers are therefore highly valued and respected for they are valuable partners in their child's education and future.

It was not lost on me that by comparison the students at this school were immeasurably better off than many other youth in Gaza who went to bed hungry, lacked the basic essentials for living a secure and healthy life, and who only dreamed of getting an education. I spoke with teachers and officials working with these schools and all highlighted the magnitude of the challenge across Gaza in providing schooling when essential services are unreliable; teaching resources are difficult to acquire beyond the rudimentary; and warfare is forever on the horizon. And all the while such deprivation increases the risk of fermenting another generation of young people who see no way forward other than through violence. Lack of hope, combined with economic deprivation makes a lethal combination.

One evening after the missiles had ceased, I went for a walk into the city center where I met two young university students in a coffee shop. We spoke for a long time, all the while drinking very strong coffee! They had never been out of the Gaza Strip, which to me was unfathomable, and to them my world was unimaginable. I asked about their country, their people, their suffering, wars, deaths, damage, lack of fuel, lack of power, lack of medicine and food, and about hope. They spoke with honesty and pain in their eyes, but also with cautious optimism for the future. For all they had experienced, they seemed devoid of bitterness or hatred; although clearly they wished their world wasn't as it is. When I asked them about this they were nonchalant, perhaps fatigued by the years of struggle, but also perhaps they could see no alternative but to look forward, for to look backwards was painful and not productive. Interestingly, from my perspective, they spoke positively of their 
education and current university studies as the one constant in providing them with purpose and hope for a better future.

One of the unexpected benefits from my work with the school was the subsequent desire by teachers and students in our group of schools to liaise with the school in Gaza through virtual learning communities. This proved to be a powerful motivator and catalyst for partnerships where ideas and resources were shared across a common platform, and where deeper learning took place for students and teachers across multiple locations. The power of "school to school" connection is a potent facilitator of understanding and action. The direct link with the Gaza students provided our students in Dubai with a reality check outside their comfort zone and thus heightened awareness and empathy. Like the trip to Ireland referenced earlier, building relationships such as these, whether virtual or in person, provide seeds of hope for communities to build understanding beyond mere tolerance.

Media is a powerful tool and in my hotel room each night I watched Western and Arabic news outlets present the same war, the same statistics, and the same loss of life in different ways. Different perspectives were characterized by the prevailing political imperatives, but where was the truth? Without a framework of reference, how would students analyze and interpret this information and seek their own truth and meaning? These questions complete the circle and take us back to the centrality of teaching and curriculum, for discernment is no accident. At that time, social media was just beginning and therefore was not the powerful tool for exposure and information dissemination that it is now.

In my final day at the school I spoke at the Year 12 graduation ceremony, which was a moving and inspiring occasion. In a hotel surrounded by ramshackle homes and poverty came together families of 17 graduates to celebrate their achievements. The graduates were each given the opportunity to speak for a few minutes. They spoke eloquently from the heart thanking parents, extended family, friends and teachers. Each of them, one by one, expressed a desire to study further and return to their precious homeland to make a contribution for a better future. They did not use this opportunity to ferment hatred or belligerence, but rather to spread hope and optimism, of making Gaza a better place for future generations. Clearly their families contributed significantly to the confident young people before me, but the school and its culture must also share credit for the passion and ongoing desire to learn which permeated so strongly on this night. Then what were the features of the school culture that contributed to the development of these remarkable young people? First and foremost was dedication from staff, the sense of community and school being a safe haven in a dangerous place, where students could be part of the solution through expressing opinions and questioning the status quo. There also existed a strong sense of purpose and high expectations. It would be dishonest and naïve of me to say that all was well in the school, for it had its challenges and not all students succeeded or were at peace with their world, but overwhelmingly the environment was positive and students were able to experience "normality" within the school walls. It was this sense of "normality" where children could do what children should do, play, run, chase, make music, scream and shout, draw, laugh and cry, that enabled them to see in among the madness, a glimmer of hope. It was here at school where community came alive, where it was safe to dream big and where adults gave care and hope, not violence and hurt. It was at school where the impossible was within reach.

When it came time for my speech, I looked out from the podium and what I saw in front of me was 17 young adults excitedly ready to take the next step in their journey, while in the distance I could see a darkened and scarred city, a people in torment, despair and pain. For as these students celebrated a significant milestone, there were so many children just like them in homes suffering intergenerational despair, and what might become of them I wondered? I spoke of many things when my turn came, but mostly of the humility I had experienced in listening to the students speak eloquently of their hopes and aspirations, not only for themselves, but poignantly for their homeland. My words felt hollow, for they had experienced loss and faced the challenges of living in a volatile and dangerous place, and it was they who would shape the next generation. It is they who are the hope of the future, along with their teachers and parents, for together they will shape the minds of those who are to follow. Without

Journal of Contemporary Issues in Education, 2016, 11(1), pp. 79-85 
this hope, there is nothing but more of the same to come. Without this hope their words on graduation night become an epitaph to another lost generation. Without this hope the school bell may as well ring no more. 